\section{Revisiting the supernumerary: the epidemiological and molecular basis of extra teeth}

\author{
P. S. Fleming, ${ }_{1}^{1}$ G. M. Xavier, ${ }_{1}^{2}$ A. T. DiBiase ${ }^{3}$ and M. T. Cobourne ${ }^{4}$
}

VERIFIABLE CPD PAPER
IN BRIEF

- Describes epidemiological features associated with human supernumerary teeth.

- Classifies human supernumerary teeth according to morphology.

- Outlines molecular signalling pathways implicated in controlling tooth number in mouse models.

- Discusses the relevance of these molecules in relation to human supernumerary teeth occuring in isolation or as part of identified syndromes.

\begin{abstract}
Supernumerary teeth are a common clinical and radiographic finding and may produce occlusal and dental problems. The aetiological basis of extra teeth is poorly understood in human populations; however, the mouse provides a useful model system to investigate the complex genetics of tooth development. This article describes recent advances in our understanding of the genetic basis of supernumerary teeth. We have reviewed biological evidence that provides insight into why supernumerary tooth formation may occur. Indeed, many of the molecular signalling pathways known to be involved in normal development of the tooth germ can also give rise to additional teeth if inappropriately regulated. These include components of the Hedgehog, FGF, Wnt, TNF and BMP families, which provide a useful resource of candidate genes that may potentially play a role in human supernumerary tooth formation.
\end{abstract}

\section{Introduction}

Supernumerary teeth are those present in addition to the normal complement within the dentition and can occur singly or in multiples, unilaterally or bilaterally and within the maxilla or mandible. ${ }^{1}$ Individual supernumerary teeth are more common in the permanent dentition where they demonstrate a clear predilection for the anterior and then posterior regions of the maxilla. ${ }^{2}$ In contrast, multiple supernumerary teeth occur more commonly in the mandibular premolar region. ${ }^{3}$ The eruption, orientation and morphological features associated with supernumerary teeth show wide variation. They may erupt normally or fail to erupt, have a normal or ectopic position, or develop an abnormal path of eruption. ${ }^{4}$ Their shape and size may be consistent with the dentition in the region of jaw in which they are localised, or may bear little or no resemblance. The

\footnotetext{
Senior Specialist Registrar, ${ }^{3}$ Consultant in Orthodontics, Department of Orthodontics, East Kent Hospitals NHS Trust; ${ }^{2} \mathrm{PhD}$ student, ${ }^{4 *}$ Reader/Honorary Consultant in Orthodontics, Department of Orthodontics and Craniofacial Development, King's Dental Institute, King's College London

${ }^{*}$ Correspondence to: Dr Martyn T. Cobourne Email:martyn.cobourne@kcl.ac.uk
}

\section{Refereed Paper}

Accepted 8 October 2009

DOI: $10.1038 /$ sj.bdj.2009.1177

${ }^{\circledR}$ British Dental Journal 2010; 208: 25-30

\begin{tabular}{|c|c|}
\hline Syndrome & Gene \\
\hline Cleidocranial dysplasia $(119600)^{8,9}$ & RUNX2 (600211) \\
\hline Ehlers-Danlos Type IV (225400)61 & PLOD (153454) \\
\hline Ellis-Van Creveld (225500) ${ }^{62}$ & $\operatorname{EVC}(604831)$ \\
\hline Fabry disease $(301500)^{63}$ & GLA (300644) \\
\hline Familial adenomatous polyposis (Gardner) (175100)10,11 & APC (611731) \\
\hline Incontinentia pigmenti (308300) $)^{64}$ & NEMO (300248) \\
\hline
\end{tabular}

local effects of these teeth upon the dentition can also differ, often relating to the position, morphology and eruption of the supernumerary tooth itself. ${ }^{5}$ Potential complications associated with supernumeraries include local effects upon the developing occlusion (crowding, spacing, impaction, displacement or rotation), cystic formation and resorption of adjacent teeth.

\section{Epidemiology}

In the permanent dentition, supernumeraries are seen in 0.1 to $3.2 \%$ of the population, being more common in males and with a relative frequency of around 2:1 in Caucasians. ${ }^{6}$ Multiple supernumerary teeth can also present as a feature of a wider developmental disorder (Table 1), including cleft lip and palate, ${ }^{7}$ cleidocranial dysplasia, ${ }^{8,9}$ and familial adenomatous polyposis. ${ }^{10,11}$ It is rare to find multiple supernumeraries in individuals with no other associated disease or syndrome, although some individual cases have been reported. ${ }^{3,12,13}$ In contrast to the permanent dentition, supernumeraries in the primary dentition are less common, having a prevalence ranging from $0.06-0.8 \%$ with no associated sexual dimorphism. This may be related to the fact that these teeth generally demonstrate normal morphology, eruption and alignment, and in a spaced primary dentition can go unreported.

\section{Classification}

Supernumerary teeth are generally classified according to morphology (Fig. 1) or location. A basic morphological classification grades supernumeraries according to normality of shape. ${ }^{14}$ Supplemental refers 
to those with essentially normal size and shape, while rudimentary (or dysmorphic) describes smaller teeth of abnormal shape. Rudimentary supernumeraries include conical, tuberculate and molariform types. This morphological classification can be further refined into four components. Conical supernumeraries are small and pegshaped, usually presenting as a mesiodens in the anterior maxilla and being one of the commonest variants of supernumerary in the permanent dentition, accounting for 75-78\% of all cases. ${ }^{2,4}$ Tuberculate supernumeraries are large, late-forming, often paired and barrel-shaped teeth, normally located on the palatal aspect of the maxillary central incisors, which account for up to $12 \%$ of supernumeraries. ${ }^{4}$ They are often responsible for the impaction of permanent maxillary incisors. ${ }^{2,3}$ Supplemental teeth are duplications within the normal dentition, arising at the end of a tooth series. The most common supplemental tooth is the permanent maxillary lateral incisor, but supplemental premolars and molars can also occur. In the primary dentition, the majority of supernumerary teeth are supplemental and usually erupt. Finally, odontomes are hamartomatous malformations, which contain calcified tissues of dental origin and may either be compound or complex in type. Compound odontomes are commonly found in the anterior maxilla and contain numerous discreet tooth-like structures. In contrast, complex odontomes are composed of a random assortment of poorly-formed dental tissues and most often located in the premolar and molar dentitions.

\section{Management}

The management of supernumerary teeth will depend upon the clinical presentation and should be considered in conjunction with any underlying malocclusion. No active treatment may be necessary if these teeth are grossly displaced and not affecting the occlusion, orthodontic treatment is not planned or there is an absence of any related pathology. Common indications for the removal of supernumerary teeth include delayed eruption or gross displacement of permanent teeth; the presence of pathology (cystic formation or resorption of adjacent teeth) or where eruption of the supernumerary has taken place and produced a malocclusion. Where supernumerary teeth
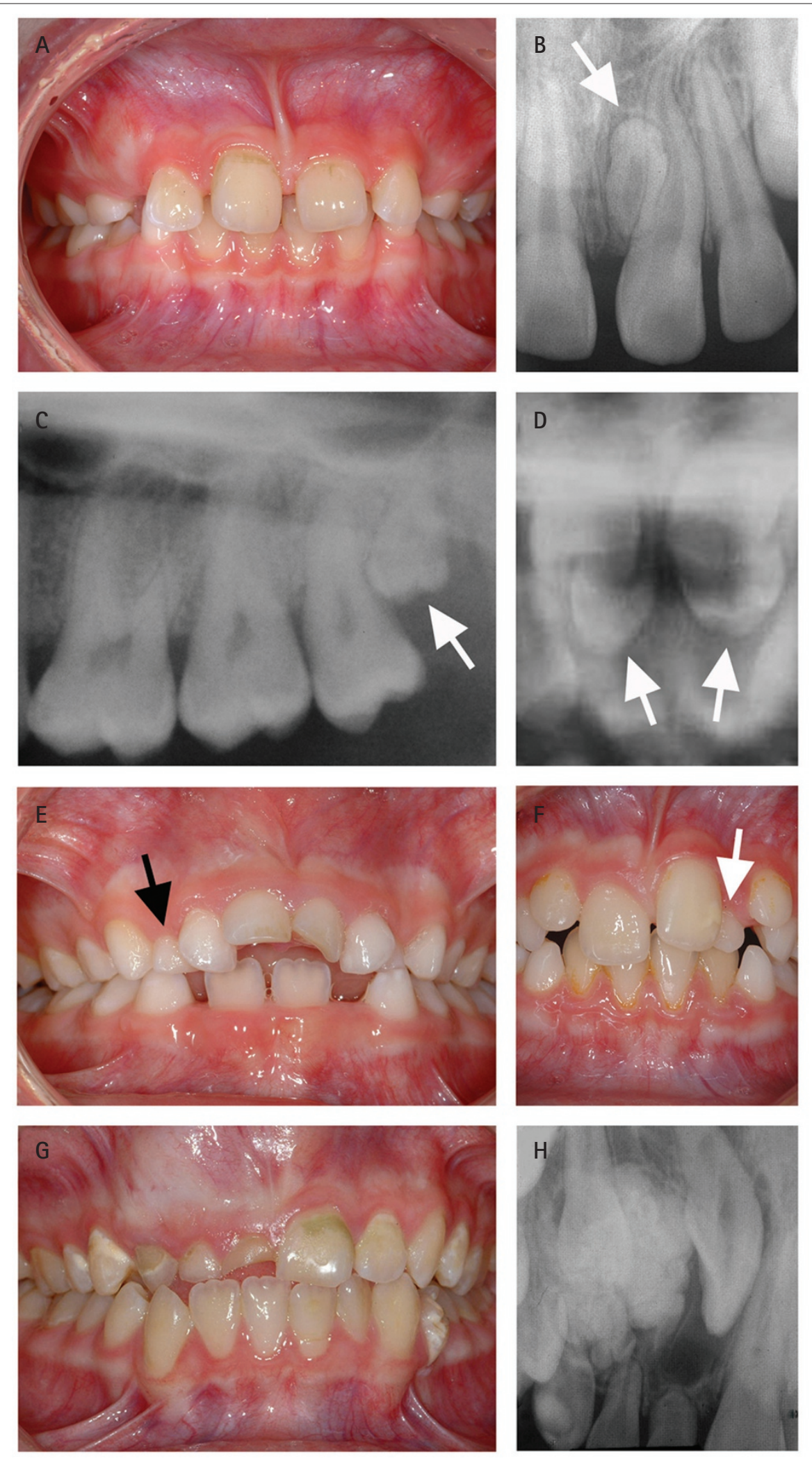

Fig. 1 Supernumerary teeth. (A, B) Unerupted mesiodens (arrowed in B) producing a midline diastema in the mixed dentition. (C) Distomolar (arrowed) in the secondary dentition. (D) Unerupted tuberculate supernumeraries (arrowed) in the anterior maxilla of a mixed dentition. $(E, F)$ Supplemental supernumerary lateral incisors in the primary $(E$, arrowed) and secondary $(F$, arrowed) dentitions. $(G, H)$ Odontome in the anterior maxilla of a mixed dentition preventing eruption of the UR1, 2, 3

have contributed to failure of eruption, removal may be performed in isolation or in conjunction with surgical exposure of the impacted tooth. If space is available in the arch, removal of the supernumerary alone may facilitate normal eruption of 

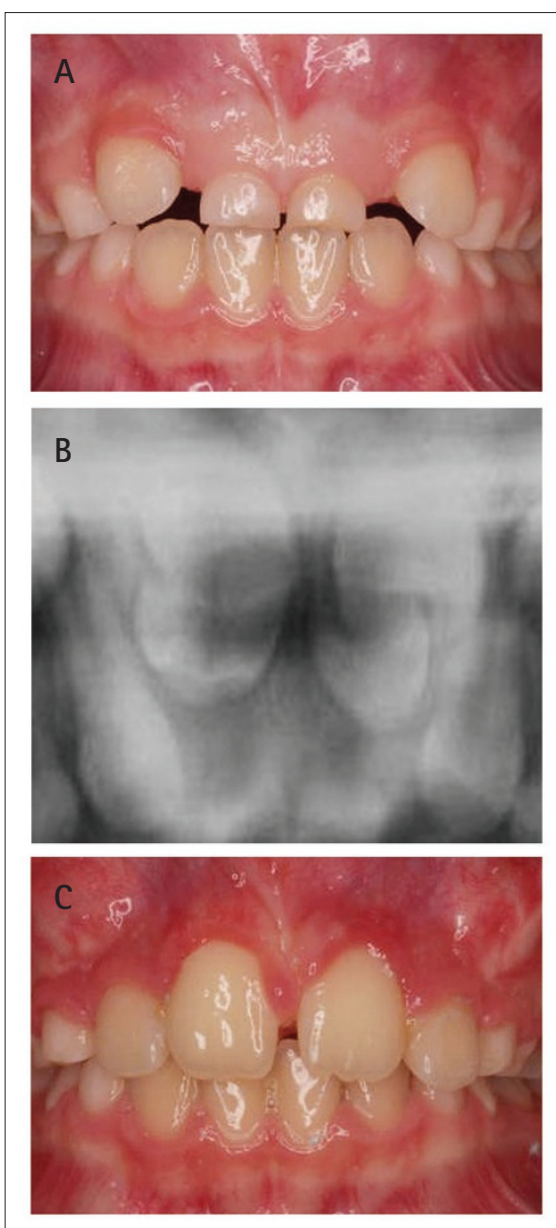

Fig. 2 Impaction of both maxillary central incisors due to the presence of paired tuberculate supernumeraries in the anterior maxilla. Both supernumeraries were removed and the central incisors erupted following surgical exposure, bonding and orthodontic traction. (A) Pre-treatment. (B) Radiographic appearance. (C) Post-treatment

the impacted tooth. Retrospective analyses have suggested that up to $90 \%$ of impacted incisors will erupt following removal of the supernumerary within 18 months, with around 30\% requiring orthodontic alignment. ${ }^{15-17}$ However, spontaneous eruption is unlikely to occur if insufficient space exists in the dental arch, or the impacted tooth is significantly displaced and in these cases, orthodontic treatment involving space creation and traction may be required. Moreover, tuberculate supernumeraries, odontomes and those seen in older patients with more advanced root development are also less likely to be associated with spontaneous tooth eruption following supernumerary removal ${ }^{18}$ (Fig. 2).

\section{Why do supernumerary teeth form?}

The aetiological basis of supernumerary teeth is poorly understood; however, there is clearly an important genetic component. Supernumeraries run in families, demonstrate racial variation and display sexual dimorphism. ${ }^{6}$ However, some of the most compelling evidence for a genetic basis is the fact that supernumerary teeth can also be a prominent feature of many developmental disorders.

\section{Molecular mechanisms controlling early tooth development}

Early tooth development is mediated in the embryo by a series of signals that take place between tooth-forming epithelium and neural crest-derived ectomesenchyme of the early jaws. ${ }^{19}$ Initiation of tooth development is a key process in regulating tooth number, characterised by localised proliferation of the oral epithelium producing a dental lamina that invaginates into the underlying jaw mesenchyme to form a tooth bud. Once the tooth bud has formed, inductive potential for future tooth development switches to the underlying mesenchyme. ${ }^{19-21}$ In humans, the deciduous dentition is formed de novo from a number of dental laminae, which arise from the primary epithelial band of the early oral cavity, from around six weeks of development. Successional incisors, canines and premolars of the permanent dentition develop as lingual extensions of these primary laminae between 20 weeks in utero and ten months of age. In contrast, the accessional permanent molar teeth form from a backward extension of the primary dental lamina between embryonic week 14 and five years of age. ${ }^{22}$

Most current knowledge regarding tooth development is based upon mouse embryogenesis. Unfortunately mice do not provide a perfect model for development of the human dentition as they only develop a single, highly-reduced and primary dentition during their lifetime, which lacks both premolars and canines. Instead, an edentulous region or diastema exists between the molars and incisors where very early rudimentary tooth buds are known to form in both the molar and incisor fields, but which quickly regress through programmed cell death. ${ }^{23}$ However, the tight regulation of tooth initiation that occurs in these regions of the mouse jaw has provided useful insight into how tooth number is controlled at the molecular level. In particular, a growing number of mutant mouse lines have been described where diastema tooth development continues beyond the bud stage and additional teeth are able to form in this region.

\section{Initiating tooth development}

In the mouse embryo a number of very early signalling interactions between the oral epithelium and neural crest cells that have migrated into the early jaws are thought to establish pattern information along the developing dental axis. ${ }^{24}$ A key feature during the initiation of murine tooth development is the localised and restricted expression of a signalling molecule called Sonic Hedgehog (Shh) in the earliest epithelial thickenings of the future teeth. At this stage, Shh acts as a mitogen essential for normal proliferation of the tooth bud as it invaginates; in the absence of normal Shh signal transduction during this time, tooth development arrests. ${ }^{25,26}$ Appropriate restriction of Shh activity along the axis of the developing jaws is therefore important to ensure the correct number of teeth form in the right positions. ${ }^{26,27}$ However, there is now evidence from a number of mouse mutants to suggest that inappropriate regulation of Shh activity might also play a key role in the formation of supernumerary teeth.

Once the early tooth bud has formed, continued and reiterative signalling between epithelium and mesenchyme allows further growth and morphogenesis, with progression of the bud stage tooth germ into cap and bell stages. ${ }^{21}$ This process is controlled primarily by the primary enamel knot; a discreet, non-proliferating and transient signalling centre, which appears within the tooth germ epithelium at the cap stage and is intimately involved with regulation of tooth shape. The primary enamel knot expresses a number of signalling molecules and is essential for normal progression of tooth development. In vestigial teeth of the mouse diastema the primary enamel knot does not form because these putative buds rapidly disappear due to localised cell death. ${ }^{23}$ In the developing molar dentition, multiple secondary enamel knots also form during the bell stage, following disappearance of the primary knot, and these structures fine-tune cuspal shape of the future crown. 


\section{Hedgehog signalling}

Hedgehog signal transduction through Shh is clearly important during normal tooth initiation; however, there is evidence to suggest that this pathway can also influence tooth number. Hedgehog signals are mediated in responding cells by primary cilia, specialised single organelles that project from the surface of all eukaryotic cells. Mutations in a number of genes, including the ciliary protein IFT88/ Polaris, which encode essential functional components of primary cilia can lead to changes in Hedgehog signal activity and supernumerary teeth in mice. ${ }^{28}$ Mice carrying an allele of IFT88/Polaris encoding a protein with only partial function have supernumerary teeth resembling premolars in the diastema region of both jaws, which are specific to a loss of Polaris and increased range of Hedgehog signal within the dental mesenchyme. ${ }^{29}$ Further evidence that upregulation of Shh activity in the diastema mesenchyme can produce ectopic tooth formation is found in mice mutant for another molecule called Gas1, which encodes a Shh proteinantagonist in this region. ${ }^{27}$ Gas 1 mutants also have ectopic diastema teeth in both the mandible and maxilla, which resemble premolars (Fig. 3) and are accompanied by increased Shh signal activity within this region. ${ }^{29}$

Another link between Hedgehog signal transduction and the presence of additional teeth has been provided by Runx 2 mutant mice. In humans, cleidocranial dysplasia is an autosomal dominant condition characterised by defective bone ossification in combination with severe dental anomalies, which include multiple supernumerary teeth (Fig. 4). Cleidocranial dysplasia occurs as a result of mutation in the Runt-related transcription factor RUNX2, which is essential for the normal differentiation of bone-forming osteoblasts. ${ }^{30,31}$ In the mouse, Runx2 is expressed in the mesenchymal compartment of the tooth and a complete loss of function is associated with arrested tooth development; ${ }^{32}$ however, in the heterozygous mutant, which models the human genotype, rudimentary supernumerary tooth formation takes place lingual to the first molar tooth germs. The mechanism underlying this is not fully understood but in the lower molars at least, Runx2 transcription in the mesenchyme is able to repress Shh signalling in
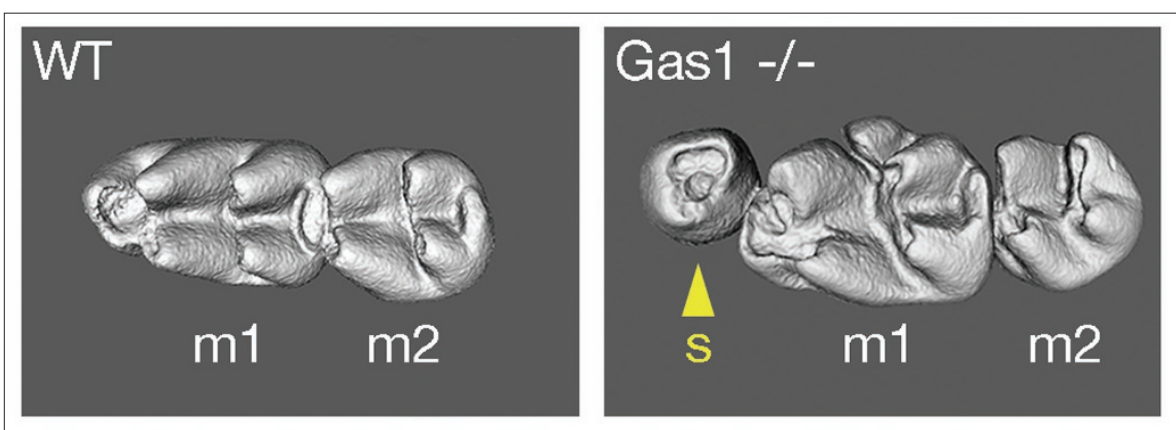

Fig. 3 Micro CT analysis comparing the molar dentitions of wild type and Gas 1 mutant mice. (A) In the wild type, there are two molar teeth present $(\mathrm{m} 1, \mathrm{~m} 2)$; in the mutant there are two molar teeth $(\mathrm{m} 1, \mathrm{~m} 2)$ but also the presence of a supernumerary premolar-like tooth (s, yellow arrowhead) anterior to the first molar

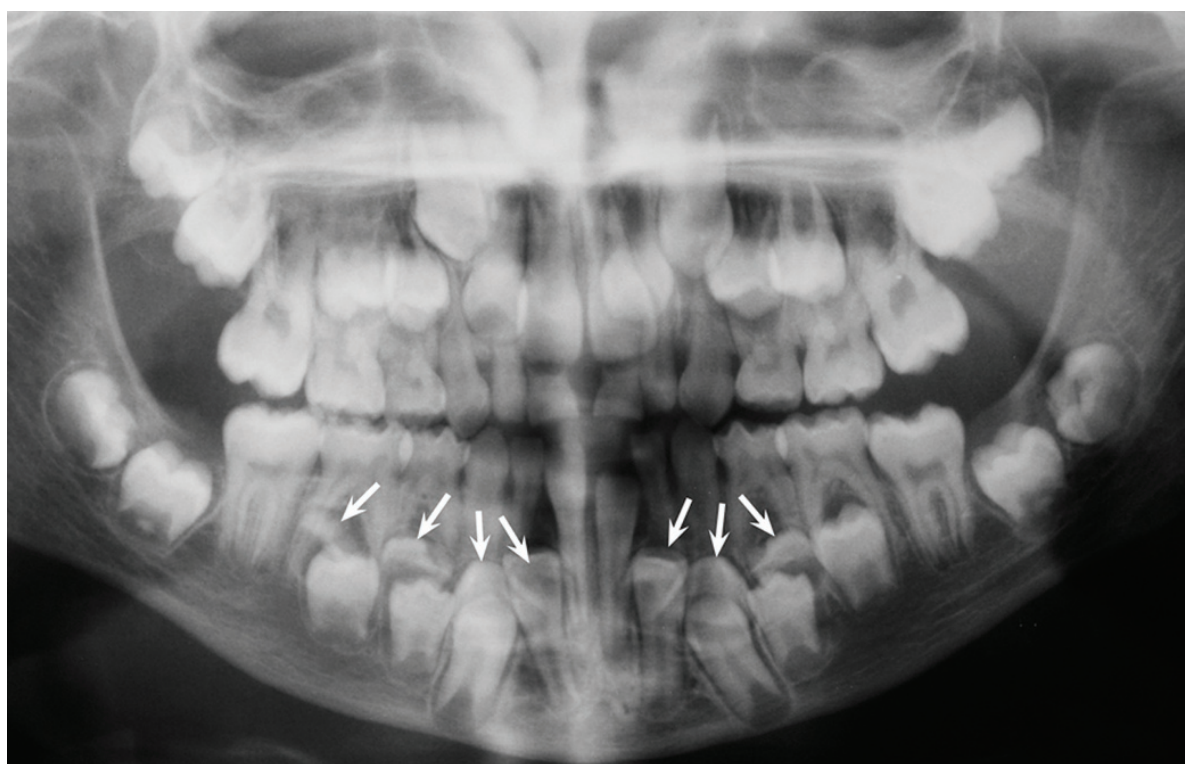

Fig. 4 Dental panoramic radiograph showing the oral manifestations of cleidocranial dysplasia. There is retention of the primary dentition, delayed eruption of the secondary dentition and the presence of multiple supernumerary teeth (arrowed)

the epithelium..$^{33}$ Thus, in the absence of adequate suppression of Hedgehog transduction in these mice, additional teeth are able to initiate in these regions.

\section{Fibroblast growth factor signalling}

The Fibroblast Growth Factor (FGF) family of secreted signalling molecules have been known to be important candidates for regulating growth and morphogenesis of the tooth germ for some time. Fgf4 and Fgf9 in the primary enamel knot epithelium can induce proliferation of both dental epithelium and mesenchyme, whereas Fgf3 and Fgf10 in the underlying mesenchyme only stimulate cell division in dental epithelium..$^{34,35}$ Importantly, there is also evidence that signalling from Fgf3 and Fgf10 in mesenchyme of the tooth bud is also required for Shh expression in the primary enamel knot epithelium. ${ }^{36,37}$
Sprouty (Spry) genes encode a small group of intracellular FGF antagonists which are produced in response to FGF signalling and therefore modulate transduction in target cells. ${ }^{38}$ Among these genes, Spry2 and Spry4 are expressed in epithelium and mesenchyme of the developing tooth, respectively, and a loss-offunction associated with either gene results in the formation of extra teeth within the diastema region of the mouse dentition, predominantly affecting the mandible. ${ }^{39}$ These teeth form following the survival and further development of the early diastema tooth buds, which normally disappear. An absence of Spry2 function in the early diastema bud epithelium sensitises this region to FGF signalling from the underlying mesenchyme, which results in continued Shh expression in the enamel knot and progression of tooth development. Another 
important signalling molecule expressed in the enamel knot is Fgf4, which signals to the underlying mesenchyme. There is good evidence that Spry4 expression in the diastema bud mesenchyme is responsible for repressing the response to FGF signalling in this region and in its absence, supernumerary teeth also form. However, in the case of Spry4, penetrance of this phenotype is significantly reduced when compared to Spry2, and for both genes the effects are restricted to the mandibular dentition. ${ }^{39}$ Nonetheless, these studies have demonstrated that modulation of molecular signalling pathways in different compartments of the tooth germ can lead to a rescue of tooth development in the mouse diastema region, preventing the large scale apoptosis that takes place in this region and allowing continued proliferation within the tooth bud to form a functional cap stage tooth germ. ${ }^{40}$

\section{Tumour Necrosis Factor pathway}

The ectodermal dysplasias represent a group of conditions characterised predominantly by defective teeth, hair and sweat glands. Hypohidrotic or anhidrotic forms are the most common and among these, $\mathrm{X}$-linked recessive hypohidrotic ectodermal dysplasia (XLHED; OMIM 305100) is seen most frequently. ${ }^{41}$ Affected males have severe hypodontia and microdontia, alopecia and hypoplastic or aplastic sweat glands. These hypohidrotic forms are caused by disruption to Ectodysplasin (EDA) signalling, which forms one component of the Tumour Necrosis Factor (TNF) pathway and is active in organs that develop via signalling between epithelium and mesenchyme. ${ }^{42}$ In humans, XLHED is caused by mutation in the gene encoding the EDA ligand (EDA1) (Xq12-13.1), ${ }^{41}$ while mutation in the EDA-receptor can cause both autosomal dominant and recessive forms. ${ }^{43}$ A number of naturally occurring, spontaneous mouse mutants very accurately replicate the features of human hypohidrotic ED; having absent or abnormally shaped teeth, a lack of sweat glands and regional alopecia.

Although teeth, hair and sweat glands would at first glance appear to be a very diverse group of structures, their embryonic origins are surprisingly similar. All these appendages develop from interactions between epithelial and mesenchymal tissues and the EDA signalling pathway plays a key role in this process. Crucially, the levels of EDA signalling seem to be important in determining tooth number. Overexpression of the $E d a-A 1$ splice vari$a^{4} t^{44}$ or $E d a r^{45}$ in the oral epithelium of transgenic mice produces supernumerary premolar-like teeth mesial to the first molars. These signals from the epithelium are therefore important for the initiation of tooth development and while a lack of EDA signalling results in hypodontia, too much EDA can produce the opposite phenotype of supernumerary teeth.

\section{WNT signalling}

WNT proteins form a large family of secreted ligands that can activate a number of intracellular signalling pathways. Among these, canonical signalling through stabilisation of $\beta$-catenin and activation of the Lef1 transcription factor is an important determinant of normal tooth development. Lef1 itself is essential for tooth development to progress beyond the bud stage and inhibition of WNT signalling arrests odontogenesis. ${ }^{46}$ However, there are now a number of lines of evidence to suggest that normal regulation of this pathway is also an important determinant of tooth number. Overexpression of Lef1 in the oral epithelium of transgenic mice produces multiple invaginations in the toothforming regions. ${ }^{47}$ Moreover, mice lacking the function of Epiprofin, a transcription factor highly expressed in the epithelial component of the tooth germ have multiple supernumerary incisor and molar teeth. ${ }^{48,49}$ The formation of these supernumeraries appears to take place after initiation during the bud stage of development, with multiple branched invaginations forming at sites within the primary tooth buds. Significantly, these invaginations are associated with upregulated and extended Lef1 expression within the mesenchymal component of these tooth germs. ${ }^{48,49}$ Lef1 lies directly downstream of $\beta$-catenin, which forms the central component of a cell adhesion complex essential for canonical WNT signalling within the cell. Transgenic mice expressing a stabilised form of $\beta$-catenin throughout the oral epithelium demonstrate multiple odontomalike supernumerary teeth, with the tooth buds that give rise to these teeth undergoing a process of continuous renewal ${ }^{50}$ and being able to regulate numerous mediators of tooth development. ${ }^{51}$ In addition, there is also a firm link between unregulated WNT signalling and hyperdontia in human populations. Familial adenomatous polyposis is an autosomal dominant disorder characterised by multiple adenomatous polyps of the colon and rectum, which can progress to colorectal carcinoma if not surgically removed. Multiple supernumerary teeth, odontomas and tooth impactions also affect a proportion of these patients ${ }^{10,11}$ and the causative APC tumoursuppressor gene ${ }^{52,53}$ is a known inhibitor of WNT signalling. ${ }^{54}$

\section{Bone Morphogenetic Protein signalling}

The Bone Morphogenetic Protein (BMP) family comprises a large group of proteins and among these, Bmp4 is essential for normal tooth development. Bmp4 is required to induce a number of target genes in dental mesenchyme including Msx 1, and breakdown in these inductive interactions arrests tooth development at the bud stage. ${ }^{55-57}$ Ectodin is a secreted Bmp-antagonist widely expressed in the developing tooth germ but noticeably absent from the enamel knots. Mice lacking functional Ectodin have a number of anomalies associated with the mandibular molar dentition, including the presence of a supernumerary molar tooth. Significantly, these mice also have additional incisors in the mandible, ${ }^{58-60}$ seemingly present due to a failure, in part at least, of normal Ectodin-mediated inhibition from adjacent mesenchyme. ${ }^{58}$ Interestingly, Ectodin also has the ability to inhibit WNT signalling and it is likely that correct modulation of this pathway in dental mesencyhme is also an important determinant of tooth number.

\section{Conclusions}

Supernumerary teeth represent one of the commonest developmental anomalies seen in man and while there is clearly a genetic component to their aetiology, little information currently exists on the basis of this condition in human populations. However, having been used for a number of years to study the molecular mechanisms underlying normal tooth development, the mouse is now providing information on how tooth number might 
be regulated during embryogenesis. It is clear that signalling from both epithelial and mesenchymal tissues is important and that normal regulation of these processes differs, both between the jaws themselves and different tooth fields. While the mouse dentition has lost the ability to replace teeth and undergone a reduction in tooth number during evolution, a capacity does exist in certain mutant backgrounds for these vestigial tooth rudiments to survive and form teeth.

1. Schulze C. Developmental abnormalities of the teeth and jaws. In Gorlin R J, Goldman H M (eds). Thoma's oral pathology, 6th ed. pp 96-183. St Louis, USA: Mosby Company, 1970.

2. Backman B, Wahlin Y B. Variations in number and morphology of permanent teeth in 7-year-old Swedish children. Int J Paediatr Dent 2001; 11: 11-17.

3. Yusof W Z. Non-syndrome multiple supernumerary teeth: literature review. J Can Dent Assoc 1990: 56: $147-149$

4. Rajab L D, Hamdan M A. Supernumerary teeth: review of the literature and a survey of 152 cases. Int J Paediatr Dent 2002 : 12: 244-254.

5. Garvey M T, Barry H J, Blake M. Supernumerary teeth - an overview of classification, diagnosis and management. J Can Dent Assoc 1999; 65: 612-616.

6. Brook A H. Dental anomalies of number, form and size: their prevalence in British schoolchildren. $J$ Int Assoc Dent Child 1974; 5: 37-53.

7. Vichi M, Franchi L. Abnormalities of the maxillary incisors in children with cleft lip and palate. ASDC J Dent Child 1995; 62: 412-417.

8. Jensen B L, Kreiborg S. Development of the dentition in cleidocranial dysplasia. J Oral Pathol Med 1990; 19: 89-93.

9. Kreiborg S, Jensen B L, Larsen P et al. Anomalies of craniofacial skeleton and teeth in cleidocranial dysplasia. J Craniofac Genet Dev Biol 1999; 19: 75-79.

10. Fader M, Kline S N, Spatz S S et al. Gardner's syndrome (intestinal polyposis, osteomas, sebaceous cysts) and a new dental discovery. Oral Surg Oral Med Oral Pathol 1962; 15: 153-172.

11. Wolf J, Jarvinen H J, Hietanen J. Gardner's dento-maxillary stigmas in patients with familial adenomatosis coli. Br J Oral Maxillofac Surg 1986; 24: 410-416.

12. Kalra N, Chaudhary S, Sanghi S. Non-syndrome multiple supplemental supernumerary teeth J Indian Soc Pedod Prev Dent 2005; 23: 46-48.

13. Orhan A I, Ozer L, Orhan K. Familial occurrence of nonsyndromal multiple supernumerary teeth. A rare condition. Angle Orthod 2006; 76: 891-897.

14. Primosch R E. Anterior supernumerary teeth assessment and surgical intervention in children. Pediatr Dent 1981; 3: 204-215.

15. Di Biase D D. Midline supernumeraries and eruption of the maxillary central incisor. Dent Pract Dent Rec 1969; 20: 35-40.

16. Leyland $\mathrm{L}$, Batra $\mathrm{P}$, Wong $\mathrm{F}$ et al. A retrospective evaluation of the eruption of impacted permanent incisors after extraction of supernumerary teeth. J Clin Pediatr Dent 2006; 30: 225-231.

17. Mitchell L, Bennett T G. Supernumerary teeth causing delayed eruption-a retrospective study. Br J Orthod 1992; 19: 41-46.

18. Ashkenazi M, Greenberg B P, Chodik G et al. Postoperative prognosis of unerupted teeth after removal of supernumerary teeth or odontomas. Am J Orthod Dentofacial Orthop 2007: 131: 614-619.

19. Tucker A S, Sharpe P. The cutting edge of mammalian development; how the embryo makes teeth. Nat Rev Genet 2004; 5: 499-508.

20. Cobourne M T. The genetic control of early odontogenesis. Br J Orthod 1999; 26: 21-28.

21. Jernvall J, Thesleff I. Reiterative signalling and patterning during mammalian tooth morphogenesis. Mech Dev 2000; 92: 19-29.

22. Berkovitz B K B, Holland G R, Moxham B J. Oral anatomy, embryology and histology. Edinburgh: Mosby International Ltd, 2002

23. Tureckova J, Lesot $H$, Vonesch J L et al. Apoptosis is involved in the disappearance of the diastemal dental primordia in mouse embryo. Int J Dev Biol 1996; 40: 483-489.

24. Ferguson C A, Tucker A S, Sharpe P T

Temporospatial cell interactions regulating mandibular and maxillary arch patterning. Development 2000; 127: 403-412.

25. Cobourne M T, Hardcastle Z, Sharpe P T. Sonic hedgehog regulates epithelial proliferation and cell survival in the developing tooth germ. J Dent Res 2001: 80: 1974-1979.

26. Sarkar L, Cobourne M, Naylor S et al. Wnt/Shh interactions regulate ectodermal boundary formation during mammalian tooth development. Proc Nat Acad SciU S A 2000: 97: 4520-4524.

27. Cobourne M T, Miletich I, Sharpe P T. Restriction of sonic hedgehog signalling during early tooth development. Development 2004; 131: 2875-2885.

28. Zhang $Q$, Murcia N S, Chittenden L R et al. Loss of the Tg737 protein results in skeletal patterning defects. Dev Dyn 2003; 227: 78-90.

29. Ohazama A, Haycraft C J, Seppala M et al. Primary cilia regulate Shh activity in the control of molar tooth number. Development 2009; 136: 897-903.

30. Lee B, Thirunavukkarasu K, Zhou L et al. Missense mutations abolishing DNA binding of the osteoblastspecific transcription factor OSF2/CBFA 1 in cleidocranial dysplasia. Nat Genet 1997; 16: 307-310.

31. Mundlos $\mathrm{S}$, Otto F, Mundlos $C$ et al. Mutations involving the transcription factor CBFA1 cause cleidocranial dysplasia. Cell 1997; 89: 773-779.

32. D'Souza R N, Aberg T, Gaikwad J et al. Cbfa1 is required for epithelial-mesenchymal interactions regulating tooth development in mice. Development 1999; 126: 2911-2920.

33. Wang X P, Aberg T, James M J et al. Runx2 (Cbfa 1) inhibits Shh signalling in the lower but not uppe molars of mouse embryos and prevents the bud ding of putative successional teeth. J Dent Res 2005; 84: 138-143.

34. Jernvall J, Kettunen P, Karavanova I et al. Evidence for the role of the enamel knot as a control center in mammalian tooth cusp formation: non-dividing cells express growth stimulating $\mathrm{Fgf}-4$ gene. Int $\mathrm{J}$ Dev Bio/ 1994; 38: 463-469.

35. Kettunen P, Karavanova I, Thesleff I. Responsiveness of developing dental tissues to fibroblast growth factors: expression of splicing alternatives of FGFR $1,-2,-3$, and of FGFR4; and stimulation of cell proliferation by FGF-2,-4,-8, and-9. Dev Genet 1998; 22: 374-385

36. Kettunen $\mathrm{P}$, Laurikkala J, Itaranta P et al. Associations of FGF-3 and FGF-10 with signalling networks regulating tooth morphogenesis. Dev Dyn 2000; 219: 322-332.

37. Kratochwil K, Galceran J, Tontsch S et al. FGF4, a direct target of LEF1 and Wnt signalling, can rescue the arrest of tooth organogenesis in Lef1(-I-) mice. Genes Dev 2002; 16: 3173-3185

38. Mason J M, Morrison D J, Basson M A et al. Sprouty proteins: multifaceted negative-feedback regulators of receptor tyrosine kinase signalling. Trends Cell Biol 2006; 16: 45-54.

39. Klein O D, Minowada G, Peterkova R et al. Sprouty genes control diastema tooth development via bidirectional antagonism of epithelial-mesenchymal FGF signalling. Dev Cell 2006; 11: 181-190.

40. Peterkova R, Churava S, Lesot $\mathrm{H}$ et al. Revitalization of a diastemal tooth primordium in Spry2 null mice results from increased proliferation and decreased apoptosis. J Exp Zool B Mol Dev Evol 2009; 312B: 292-308.

41. Kere J, Srivastava A K, Montonen 0 et al. X-linked anhidrotic (hypohidrotic) ectodermal dysplasia is caused by mutation in a novel transmembrane protein. Nat Genet 1996; 13: 409-416.

42. Thesleff I, Mikkola M L. Death receptor signalling giving life to ectodermal organs. Sci STKE 2002; 2002: pe22

43. Monreal A W, Ferguson B M, Headon D J et al Mutations in the human homologue of mouse dl cause autosomal recessive and dominant hypohid rotic ectodermal dysplasia. Nat Genet 1999; 22: 366-369.

44. Mustonen T, Pispa J, Mikkola M L et al. Stimulation of ectodermal organ development by Ectodysplasin-A1. Dev Biol 2003: 259: 123-136.

45. Tucker A S, Headon D J, Courtney J M et al. The activation level of the TNF family receptor, Edar, determines cusp number and tooth number during tooth development. Dev Bio/2004; 268: 185-194.

46. Andl T, Reddy S T, Gaddapara T et al. WNT signals are required for the initiation of hair follicle development. Dev Cell 2002; 2: 643-653.

47. Zhou P, Byrne $C$, Jacobs J et al. Lymphoid enhancer factor 1 directs hair follicle patterning and epithelial cell fate. Genes Dev 1995; 9: 700-713.

48. Nakamura T, de Vega $S$, Fukumoto $S$ et al. Transcription factor epiprofin is essential for tooth morphogenesis by regulating epithelial cell fate and tooth number. J Biol Chem 2008; 283: 4825-4833.

49. Nakamura $T$, Unda F, de-Vega S et al. The Kruppellike factor epiprofin is expressed by epithelium of developing teeth, hair follicles, and limb buds and promotes cell proliferation. J Biol Chem 2004; 279: 626-634

50. Jarvinen E, Salazar-Ciudad I, Birchmeier W et al. Continuous tooth generation in mouse is induced by activated epithelial Wnt/beta-catenin signalling. Proc Natl Acad Sci U SA 2006; 103: 18627-18632.

51. Liu F, Chu E Y, Watt B et al. Wnt/beta-catenin signalling directs multiple stages of tooth morphogenesis. Dev Bio/ 2008; 313: 210-224.

52. Groden J, Thliveris A, Samowitz W et al. Identification and characterization of the familial adenomatous polyposis coli gene. Cell 1991; 66: $589-600$

53. Novelli M R, Williamson J A, Tomlinson I P et al. Polyclonal origin of colonic adenomas in an $\mathrm{XO} / \mathrm{XY}$ patient with FAP. Science 1996; 272: 1187-1190.

54. Polakis P. The many ways of Wnt in cancer. Curr Opin Genet Dev 2007: 17: 45-51.

55. Chen $\mathrm{Y}$, Bei $\mathrm{M}$, Woo I et al. Msx 1 controls inductive signalling in mammalian tooth morphogenesis. Development 1996; 122: 3035-3044.

56. Tucker A S, Al Khamis A, Sharpe P T. Interactions between Bmp-4 and Msx-1 act to restrict gene expression to odontogenic mesenchyme. Dev Dyn 1998; 212: 533-539.

57. Vainio S, Karavanova I, Jowett A et al. Identification of BMP-4 as a signal mediating secondary induction between epithelial and mesenchymal tissues during early tooth development. Cell 1993; 75: 45-58.

58. Munne P M, Tummers M, Jarvinen E et al. Tinkering with the inductive mesenchyme: Sostdc 1 uncovers the role of dental mesenchyme in limiting tooth induction. Development 2009; 136: 393-402.

59. Murashima-Suginami A, Takahashi K, Kawabata T et al. Rudiment incisors survive and erupt as supernumerary teeth as a result of USAG-1 abrogation. Biochem Biophys Res Commun 2007; 359: 549-555.

60. Murashima-Suginami A, Takahashi K, Sakata T et al. Enhanced BMP signalling results in supernumerary tooth formation in USAG-1 deficient mouse. Biochem Biophys Res Commun 2008; 369: 1012-1016.

61. Melamed Y, Barkai G, Frydman M. Multiple supernumerary teeth (MSNT) and Ehlers-Danlos syndrome (EDS): a case report. J Oral Pathol Med 1994. 23: 88-91.

62. Cahuana A, Palma C, Gonzales W et al. Oral manifestations in Ellis-van Creveld syndrome: report of five cases. Pediatr Dent 2004; 26: 277-282.

63. Regattieri L R, Parker J L. Supernumerary teeth associated with Fabry-Anderson's syndrome. Oral Surg Oral Med Oral Pathol 1973; 35: 432-433.

64. Himelhoch D A, Scott B J, Olsen R A. Dental defects in incontinentia pigmenti: case report. Pediatr Dent 1987: 9: 236-239. 